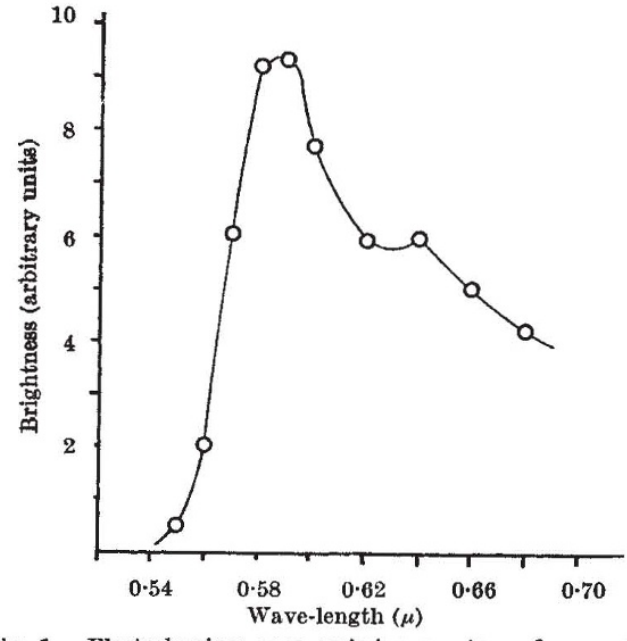

Fig. 1. Electroluminescence emission spectrum from undoped gallium phosphide crystal

approximately; the deviations have not yet been determined to be significant.

The results corroborate the observation of Wolff, Hebert and Broder, that a unique red electroluminescence is obtained from zinc-doped gallium phosphide. I have found, however, that the zine concentration is critical ; above about 0.01 per cent zinc only non-luminescent crystals are obtained. The lower limit on the zinc concentration is not known as yet. I am conducting experiments to correlate the amount of 'zinc' emission with the zinc concentration. It is possible that Grimmeiss and Koelmans did not observe the $7000 \AA$. emission because the concentration of zinc in their weakly doped crystals was too low, and in their heavily doped crystals too high.

The role of the zine impurity in the luminescent process is not known. It is tempting to draw the analogy with copper in zinc sulphide. However, junction and impurity band formation have also been shown to play an important part in carrier injection electroluminescence ${ }^{6}$, and it is conceivable that the zinc impurity is involved in this way.

I wish to acknowledge the assistance of Messrs. E. L. Peirson and C. V. Osterday in the preparation

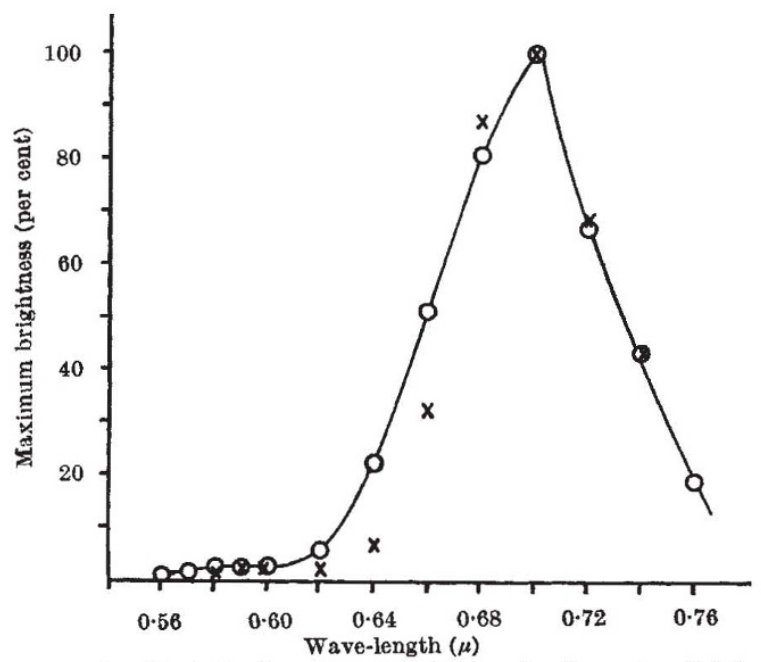
Fig. 2. Electroluminescence emission spectra from zinc-doped $\left(0\right.$, room temperature ; $x,-100^{\circ} \mathrm{C}$ of the crystals, and am particularly grateful to Prof. J. J. Dropkin for reading and commenting on this manuscript.

Frank G. Uluman

Physical Research Department,

National Cash Register Co., Dayton 9, Ohio.

${ }^{2}$ Wolff, G. A., Hebert, R. A., and Broder, J. D., Phys. Rev., 100, 1144 (1955): Semiconductors and Phosphors, 547 (Interscience, 1958). 2 Holt, D. A., Alfrey, G. F., and Wiggins, S. S., Nature, 181, 109 (1958)

${ }^{3}$ Grimmeiss, H. G., and Koelmans, H., Philips Res. Rep., 15, 290 $(1960)$.

${ }^{4}$ Gorton, H. C., Swartz, J. M., and Peet, C. S., Nature, 188, 303 (1960).

'Allen, J. W., and Gibbons, P. E., J. Elec. Control, 7, 518 (1959)

' Patrick, L., and Choyke, W. J., J. App. Phys, 80, 236 (1959).

\section{The Unit of Neutron Flux}

Wr wish to support the suggestion ${ }^{1}$ that a unit of neutron flux be defined. We feel, however, that it would be more practical to define the chad as follows :

$$
1 \mathrm{chad}=10^{12} \mathrm{n} . / \mathrm{cm} .^{2} \mathrm{sec} \text {. }
$$

The flux in most existing or contemplated power reactors lies in the range of $10^{12}-10^{13} \mathrm{n} . / \mathrm{cm} .{ }^{2} \mathrm{sec}$. the flux in zero energy reactors is generally about $10^{9} \mathrm{n} . / \mathrm{cm} .^{2}$ sec., and that encountered in sub critical assemblies is approximately $10^{6} \mathrm{n} . / \mathrm{cm} .{ }^{2}$ sec. Highflux research reactors operate at flux-levels ranging up to about $10^{16} \mathrm{n} . / \mathrm{cm} .^{2}$ sec. The whole range of applied neutron physics could therefore be covered conveniently by the chad, as defined above, and the associated units microchad $\left(10^{8} \mathrm{n} . / \mathrm{cm}^{2}\right.$ sec.), millichad $\left(10^{9}\right.$ n. $/ \mathrm{cm} .^{2}$ sec. $)$ and kilochad.

While having no objection in principle to the definition suggested earlier ( 1 chad $=1 \mathrm{n} . / \mathrm{cm} .{ }^{2}$ sec.), we feel that our definition is more practical and convenient in that, in addition to eliminating the clumsy compound nomenclature, it will remove the necessity for inclusion of large powers of 10 .

\section{S. McGirL}

D. C. Menzies

M. R. Price

U.K. Atomic Energy Authority, Development and Engineering Group, Thurso, Caithness.

I Harrison, R. D., and Thorley, N., Nature, 188, 571 (1960).

\section{CRYSTALLOGRAPHY}

\section{Some Electron Microscopic Observations on Single Crystals of Polyethylene}

Some time ago it was found that in dilute solutions of polyethylene, particularly of 'Marlex 50', single crystals may be formed which can be made visible by means of electron microscopic techniques ${ }^{1-3}$. Morphologically, these crystals showed much resemblance to single crystals of paraffin, which were observed for the first time by Dawson and Vand4: the latter show a spiral terrace growth, the height of the terraces corresponding to the length of the chain molecules.

Keller ${ }^{1}$ pointed out that the chains in the poly. ethylene crystal must necessarily be folded and that the height of the terraces corresponds to the distances between successive folds. He also noted that the crystals lose their crystallinity in the electron microscope, but that their morphological shape is probably preserved.

In an a.tempt to study undecomposed specimens, in which freshly prepared specimens were exposed 